\title{
E-COMMERCE IMPLEMENTATIONS FOR RECYCLED PRODUCTS BY SMALL MEDIUM ENTERPRISES
}

\author{
Ratna Marta DHEWI ${ }^{1}$, Stefani Nawati EKORESTI 2 , Eusi SUSILOWATI ${ }^{3}$ \\ 1 Jurusan Akuntansi UT Bogor; 2 Jurusan PAUD UT Bogor; 3 Jurusan PGSD UT Bogor, \\ 4 Email: rmdhewi@ecampus.ut.ac.id
}

\begin{abstract}
ABSTRAK
An increasing global awareness on the need for sustainable production and environmental behaviour has encouraged small medium enterprises (SME) to develop products with recycled content. However, how to sustainably marketing the recycled products has also challenged the SMEs. There is a small business managed by orphans in Bogor namely Kelompok Belajar Masyarakat (KBM) Salimah that develop recycled products from plastics and newspaper. Preliminary study has found that there has been a challenge on how to sustain the marketing activities of recycled products in this digital economy. Therefore, it is worth exploring the e-commerce to help such SME to have sustainable business for the recycled products. This research develops a business planning in utilising on line shopping, web and social media, establishing customers by email and engaging in online store, furthermore emphasizes on barriers to e-commerce implementation by the SME. The analysis of ecommerce adoption to encourage the benefits for SME and consumers will be presented.
\end{abstract}

Kata kunci: E-Commerces, $3 R$, recycled products

\section{PENDAHULUAN}

Desa Sinargalih Kec Taman Sari Kab Bogor yang berada kurang lebih 10 Km dari kaki Gunung Salak memiliki potensi alam berupa aliran mata air dari gunung salak maupun sumber mata air tanah yang melimpah. Aliran mata air ini dimanfaatkan oleh sebagian besar warga untuk membuka pemancingan dan membuka kolam renang.

Untuk menjaga mata tetap terjaga dan untuk menghangatkan suasana selama memancing maupun berenang, warga meminum kopi, meminum minuman ringan dan makan makanan ringan yang dikemas dengan menggunakan plastik kresek. Sampah plastik pembungkus minuman dan makanan yang bertebaran ini menimbulkan masalah pada pencemaran tanah dan membuat aliran air menjadi mampet. Namun saat ini masalah sampah sudah bisa teratasi oleh kreatifitas warga yatim binaan Kelompok Belajar Masyarakat [KBM] Salimah yang telah mendapatkan pelatihan dari UT Bogor. Segala jenis sampah plastik minuman dan makanan ini diubah menjadi peralatan bernilai seperti tas, kotak tisu, tamplak, dompet, bunga mawar dan lain sebagainya. Selain itu, warga yatim juga memanfaatkan koran bekas alas duduk untuk memancing dijadikan keranjang dan kotak pensil.

Jenis pemasaran yang selama ini dikenal oleh warga binaan KBM Salimah adalah jenis pemasaran konvensional. Jenis pemasaran ini dirasakan kurang memiliki peluang pasar yang luas. Oleh karena itu berdasarkan studi pendahuluan, warga ingin mengetahui lebih banyak terkait ecommerce, untuk memberikan semangat agar produksi kreatifitas ini dapat meningkat. 
Selain itu, ketidaktahuan saluran pemasaran hasil pengolahan sampah plastik dan koran yang dialami warga yatim binaan Kelompok Belajar Masyarakat [KBM] Salimah, membuat warga menjadi kurang dapat memaksimalkan pendapatannya dari berjualan hasil kerasi sampah plastik dan Koran. Hal ini selaras dengan Jauhari, 2010, bahwa pengembangan website dan e-commerce dapat dimanfaatkan sebagai sarana untuk promosi dan pemasaran produk-produk usaha, sehingga akan meningkatkan volume penjualan dan meningkatkan pendapatan.

Namun, warga menghadapi hambatan untuk penerapan teknologi informasi baru, khususnya, perdagangan elektronik. Sebagian masalah berkaitan dengan keterbatasan sumber daya dan kemampuan teknologi, skala dan keterjangkauan teknologi informasi, serta fasilitas implementasi dalam organisasi yang berkembang dan berubah dengan cepat. (Raisinghani, Melemez, Zhou, Paslowski, Kikvidze, Taha \& Simons, 2005). Warga selama ini hanya memanfaatkan kuota internet untuk WA dan Facebook padahal walaupun di desa, sinyal internet dari berbagai provider dapat dengan mudah diakses

Solusi yang ditawarkan pada PkM mandiri ini adalah memberikan Pengenalan e-commerce. Karena manfaat dan keuntungan menggunakan e-commerce adalah untuk media promosi dalam rangka untuk meningkatkan volume penjualan, baik untuk penjualan online maupun konvensional (Jansen, 2006; Supardi, 2009). Selain itu menurut Fauzia, 2016, E-commerce dan M-commerce lebih efisien karena bisa memangkas rantai penawaran, sehingga para produsen dan distributor bisa mengurangi beban dengan cara memangkas biaya-biaya yang berkaitan dengan inventory.

Pelatihan ini dimulai dengan sosialisasi keuntungan dan kelemahan e-commerce, penanyangan vidio inspiratif kisah sukses berjualan online, pelatihan membuat email dan pelatihan membuka toko online.

Target kegiatan PkM ini adalah warga belajar dapat membuat satu toko online yang mewakili desa dengan kepengurusan yang terstruktur. Sehingga dapat mengangkat nama desa dan dapat secara luas memberikan kesejahteraan kepada warga desa. Hal ini sejalan dengan (Wang, \& Cheung, 2004; Buhalis \& Schertler, 1999) bahwa semakin banyak pengguna Internet membeli online; akan memberikan dampak besar sebagai sumber informasi untuk pariwisata, sehingga akan mendapatkan pangsa pasar perdagangan online yang lebih besar.

\section{KAJIAN TEORI}

Perdagangan Elektronik (E-Commerce = electronic commerce) adalah bagian dari elifestyle yang memungkinkan transaksi jual beli dilakukan secara online dari sudut tempat mana pun (Hidayat, 2008:5). Menurut Wong (2010 : 33) pengertian dari electronic commerce adalah pembelian, penjualan dan pemasaran barang serta jasa melalui sistem elektronik. Seperti radio, televisi dan jaringan komputer atau internet. Berasarkan kedua pengertian tersebut e-commerce dapat di definisikan sebagai proses transaksi jual beli yang dilakukan secara online dengan media alat elektronik.

E-commerce memiliki beberapa manfaat, baik itu organisasi, perusahaan dan masyarakat itu sendiri, berikut beberapa manfaat dari e-commerce (Suyanto, 2003:50-51): 
a. Bagi organisasi pemilik e-commerce

1. Memperluas market place hingga ke pasar nasional dan internasional.

2. Dengan capital outplay yang minim, sebuah perusahaaan dapat dengan mudah menemukan lebih banyak pelanggan, supplier yang lebih baik dan partner bisnis yang paling cocok dari seluruh dunia.

3. E-commerce menurunkan biaya pembuatan, pemrosesan, pendistribusian, penyimpanan, dan pencarian informasi yang menggunakan kertas.

4. E-commerce mengurangi waktu antara outlay modal dan penerimaan produk dan jasa.

b. Bagi konsumen

1. E-commerce memungkinkan pelanggan untuk berbelanja atau melakukan transaksi selama 24 jam sehari sepanjang tahun dari hampir setiap lokasi.

2. E-commerce memberikan lebih banyak pilihan kepada pelanggan, mereka bisa memilih berbagai produk dari banyak vendor.

3. E-commerce menyediakan produk dan jasa yang tidak mahal kepada pelanggan dengan cara mengunjungi banyak tempat dan melakukan perbandingan secara cepat.

4. Pelanggan bisa menerima informasi yang relevan secara detil dalam hitungan detik, bukan lagi hari atau minggu.

c. Bagi masyarakat

1. E-commerce memungkinkan orang untuk bekerja di dalam rumah dan tidak harus keluar rumah untuk berbelanja. Ini berakibat menurunkan arus kepadatan lalu lintas dijalan serta mengurangi polusi udara.

2. E-commerce memungkinkan orang di negara-negara dunia ketiga dan wilayah pedesaan untuk menikmati aneka produk dan jasa yang akan susah mereka dapatkan tanpa ecommerce.

Selain itu menurut Ghandour A, 2015 Situs web E-Commerce adalah saluran penjualan antar bisnis, pelanggan, dan dunia pada umumnya. Dalam lingkungan bisnis kompetitif kontemporer, situs web yang inovatif, dirancang dengan baik dan dikelola dapat memberikan keuntungan yang dibutuhkan bisnis untuk melakukan kegiatan E-Commerce dengan sukses

Selain memiliki keunggulan, E-Commerce juga memiliki kelemahan antara lain:

a. Kelemahan segi teknis

1. Jika emplementasi buruk maka dapat terjadi kelemahan keamanan, keandalan dan standar sistem yang ada

2. Perubahan/perkembangan industri perangkat lunak sangatlah cepat

3. Jika terjadi kendala pada bandwidth, maka dapat terjadi kegagalan $\mathrm{TI}$

4. Kesulitan dalam integrasi sistem

5. Terjadi masalah pada kompatibilitas sistem

b. Kelemahan dari segi non-teknis

1. Mahalnya biaya pembuatan/pembangunan sebuah sistem E-Commerce.

2. Tingkat kepercayaan pelanggan yang kurang terhadap situs E-Commerce.

3. Sulitnya untuk memastikan keamana dan privasi dalam setiap transaksi secara online.

4. Kurangnya perasaan dalam kegiatan jual beli.

5. Aplikasi ini terus berkembang dengan sangat cepat.

6. Masih belum murah dan amannya akses Internet pada suatu negara tertentu. 
Proses transaksi E-Commerce bisa mencakup tahap-tahap sebagai berikut (Suyanto, 2003:46):

1. Show. Penjual menunjukkan produk atau layanannya di situs yang dimiliki, lengkap dengan detail spesifikasi produk dan harganya.

2. Register. Konsumen melakukan register untuk memasukkan data-data identitas, alamat pengiriman dan informasi login.

3. Order. Setelah konsumen memilih produk yang diinginkan, konsumen pun selanjutnya melakukan order pembelian.

4. Payment. Konsumen melakukan pembayaran.

5. Verification. Verifikasi data konsumen sepeti data-data pembayaran (No. rekening atau kartu kredit).

6. Deliver. Produk yang dipesan pembeli kemudian dikirimkan oleh penjual ke konsumen

Menurut Suryani (2013), Faktor-faktor yang menentukan pembelian kembali dalam berbelanja melalui online dalam persepsi customer adalah persepsi atas kemudahan dalam penggunaan; kegunaan yang dirasakan; kepercayaan; kenyamanan; pemenuhan; privasi; ketersediaan layanan; dan ketanggapan.

\section{METODE PELAKSANAAN}

Metode yang digunakan pada pemberdayaan warga yatim binaan KBM Salimah Desa Sirnagalih, Ciapus Kab bogor yaitu:

a. Penyampaian materi dengan menggunakan pendekatan pembelajaran partisipatif. Selanjutnya dalam proses pembelajaran digunakan beberapa metode pembelajaran, antara lain ceramah bervariasi, tanya jawab, dan demonstrasi.

b. Praktek lapangan yaitu memberikan pengetahuan kepada warga belajar melalui pengalaman lapangan. Pelaksanaan praktik lapangan dilakukan dengan pola sebagai berikut:

1) Warga belajar dibagi ke dalam lima kelompok-kelompok belajar. Setiap kelompok beranggotakan enam orang warga belajar.

2) Materi praktik adalah cara membuat email dan cara membuat toko online

3) Praktek dilakukan selama dua hari @ 2 jam pada tanggal 22-23 September 2018

c. Uji kompetensi. Pada akhir kegiatan PkM akan dipilih 1 dari 5 kelompok yang berkinerja baik dan dapat menghasilkan produk sesuai standar yang telah ditetapkan. Hal ini dimaksudkan agar setelah program PkM ini selesai warga dapat saling membantu untuk memberikan training for traniers [ToT] bagi warga yang lainnya.

d. Monitoring yaitu suatu kegiatan pemantauan untuk mengetahui efektifitas pelaksanaan pembelajaran, setiap selesai pemberian materi pelatihan. Apabila ada kendala atau kelemahan, maka hal ini didiskusikan oleh tim pelaksana program untuk dicarikan solusinya.

e. Evaluasi bertujuan untuk mengetahui kemajuan warga belajar dan ketercapaian tujuan pembelajaran yang dilakukan sesudah rangkaian kegiatan PkM usai. Evaluasi meliputi aspek kognitif (pengetahuan) dan keterampilan sesuai dengan materi yang telah diajarkan. 


\section{HASIL DAN PEMBAHASAN}

Desa Seinargalih secara administratif merupakan salah satu desa yang berada di Kecamatan Taman Sari. Keadaan sosial masyarakat Desa Sinargalih cukup baik, terlihat sudah banyak bangunan rumah masyarakat yang sudah seluruhnya terbuat dari bangunan yang permanen. Jalan utama yang dilalui sudah terbuat dari aspal, serta terdapat alat transportasi yang menghubungkan antar desa yang ada disekitarnya. Namun di desa tersebut jumlah warga yatim dan anak-anak putus sekolah masih sangat banyak dan terutama membutuhkan bantuan untuk pembinaan kreatifitas.

Pusat Kegiatan Belajar Masyarakat [PKBM] Salimah adalah suatu wadah yang menyediakan informasi dan kegiatan belajar sepanjang hayat bagi warga masyarakat yang lebih berdaya di desa Sinargalih. Wadah ini milik masyarakat, dikelola dari, oleh dan untuk masyarakat. PKBM ini didominasi oleh warga yatim yang tinggal di desa Sinargalih yang jumlahnya sampai ratusan orang.

Berdasarkan hasil dari need assessment warga bersama dengan pengurus PKBM Salimah, warga membutuhkan beberapa pelatihan yaitu pelatihan membuat email, pelatihan membuat toko online dengan memanfaatkan salah satu platform toko online yaitu toko pedia yang memiliki fitur yang mudah untuk digunakan dan pengetahuan terkait dengan e-commerce. Berdasarkan hasil need assestment ini maka pada PkM ini juga diberikan penanyangan vidio inspiratif kisah sukes berjualan online, agar semakin menumbuhkan motivasi bagi warga.

Kegiatan PkM mandiri ini diikuti oleh 30 orang warga yatim usia 16-40 tahun yang merupakan usia produktif. Warga belajar ini terdiri dari 20 orang perempuan dan 10 orang laki-laki. Warga belajar ini dibagi menjadi lima kelompok. Per kelompok berjumlah enam orang. Maksud pembagian kelompok ini adalah agar memudahkan proses transfer knowledge dan mempersiapkan warga agar dapat melaksanakan Training for trainers [TOT] bagi warga lain setelah usai kegiatan PkM ini.

Saat ini internet bukanlah barang mahal lagi bagi masyarakat, dua pertiga warga belajar sudah terbiasa menggunakan akses internet melalui HP androidnya. Namun akses internet ini baru dimanfaatkan sebatas penggunaanya untuk Whats up [WA] dan Facebook saja. Warga belum memanfaatkannya untuk menghasilkan pundi-pundi uang secara online. Terlebih pelatihan mengolah sampah bekas plastik dan koran baru beberapa hari diperoleh dari kegiatan PkM UT Bogor.

Oleh karena itu, untuk menunjang semangat dan mempertinggi tingkat produksi kreatifitas warga dalam mengolah barang bekas, PkM mandiri ini hadir untuk memberikan solusi alternatif pemasaran melalui media online. Hal ini dikarenakan sebagian besar warga tidak tau kemana harus memasarkan barang hasil kerajinan tangan mereka. Kegiatan PkM mandiri ini diikuti oleh warga belajar dengan sangat antusias. Warga secara bersama-sama dan saling membantu membuat email dan mencoba untuk membuat toko online.

Setelah kegiatan PkM berakhir, tim PkM mandiri melakukan uji kopetensi terhadap lima kelompok warga belajar. Dari hasil uji kompetensi ini dipilihlah 1 kelompok yang telah berpartisipasi baik dan menghasilkan produk pelatihan sesuai standar yang telah ditetapkan bersama. Keenam orang ini kemudian diajak untuk menandatangani perjanjian bahwa mereka akan bersedia memberikan training for traniers [ToT] bagi warga lainnya.

Berdasarkan hasil evaluasi dan monitoring kegiatan yang dilakukan sebanyak dua kali, yaitu setelah selesai pembelajaran; teori dan pembelajaran praktik, dari 30 orang warga belajar, $90 \%$ nya dapat menyelesaikan kegiatan pembelajaran. Selain itu warga belajar sekarang sudah memiliki kompetensi sebagai berikut: 
1. Mengetahui hal-hal terkait e-commerces.

2. Dapat mengoperasikan komputer dan HP Android.

3. Dapat membuat email pribadi.

4. Mengetahui cara membuat toko online yang baik dengan memanfaatkan fitur-fitur jual beli online melalui toko pedia.

Selain itu seusai pemberian PkM ini, warga belajar menyatukan tekat untuk secara bersama membuat satu toko online yang mewakili desa dengan kepengurusan yang terstruktur. Sehingga dapat mengangkat nama desa dan dapat secara luas memberikan kesejahteraan kepada warga desa. Harapan dari warga dengan meningkatnya kesejahteraan ekonomi, warga produktif dapat melanjutkan ke jenang pendidikan yang lebih tinggi dan fleksibel seperti Universitas Terbuka.

\section{KESIMPULAN}

Kesimpulan dari kegiatan PkM ini adalah:

1. Warga menjadi lebih bijak dalam menggunakan kuota internet

2. Warga memiliki pengetahuan alternatif untuk berjualan secara online

3. Warga merasa tertantang untuk membuat toko online atas nama desa dan mengkoordinir kreatifitas olah sampah ini secara lebih terstruktur agar semakin banyak warga yang merasakan manfaatnya secara ekonomi.

\section{DAFTAR PUSTAKA}

Buhalis, D., \& Schertler, W. (1999). Information and Communication Technologies in tourism, Enter'99, Wien-New York. Springer-Verlag.

Ghandour Ahmad. (2015). Ecommerce Website Value Model For SMES. International Journal of Electronic Commerce Studies. Vol.6, No.2, pp. 203-222.

Hidayat, Taufik. (2008). Panduan Membuat Toko Online dengan OSCommerce. Jakarta: Mediakita. Jansen, B.J. (2006). The Comparative Effectiveness of Sponsored and Nonsponsored Links for Web

E-commerce Queries. ACM Transactions on the Web, Vol. 1, No. 1, Article 3.

Jauhari Jaidan. (2010). Upaya Pengembangan Usaha Kecil Dan Menengah (UKM) dengan

Memanfaatkan E-Commerce. Jurnal Sistem Informasi (JSI), VOL. 2, NO. 1, April 2010.

Raisinghani, M., S., Melemez, T., Zhou, L., Paslowski, C., Kikvidze, I., Taha, S., and Simons, K. (2005). EBusiness Models in B2B: Process Based Categorization and Analysis of B2B Models, International Journal of E-business Research, 1(1), 16-36.

Supardi, Julian. (2009). Rancang Bangun Collaborative System Pemasaran Hotel Secara online Dengan Pendekatan Mediator based. Jurnal Sistem Informasi Fasilkom Unsri Vol 1 No 2.

Suryani Tatik. (2013). Perilaku Konsumen di Era Internet, Implikasinya Pada Strategi Pemasaran. Yogyakarta: Graha Ilmu.

Suyanto M. (2003). Strategi Periklanan pada e-Commerce Perusahaan Top Dunia. Yogyakarta: Andi.

Wang, S., \& Cheung, W. (2004). "E-Business adoption by travel agencies: Prime candidates for mobile ebusiness": International Journal of Electronic Commerce, 8, 43-63.

Wong, Jony. (2010). Internet Marketing for Beginners. Jakarta: Elex Media Komputindo 